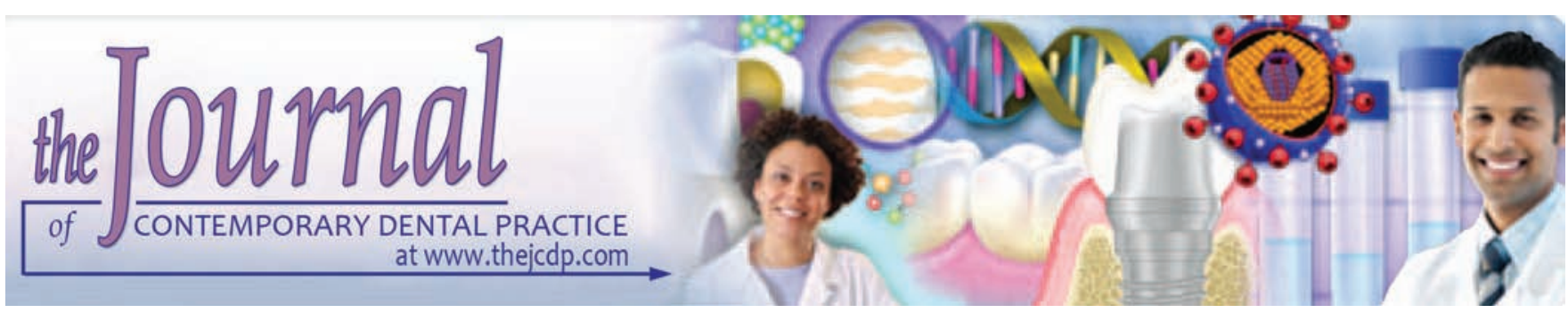

\title{
Association of Palatal Rugae Pattern in Gender Identification: An Exploratory Study
}

\author{
${ }^{1}$ Nitin Gautam, ${ }^{2}$ Suneel G Patil, ${ }^{3} \mathrm{R}$ Gopi Krishna, ${ }^{4}$ Hemalatha Agastya, ${ }^{5}$ Lubna Mushtaq, ${ }^{6} \mathrm{~K}$ Vijay Kumar
}

\begin{abstract}
Aim: The present study's aim was to assess the pattern of palatine ridges/rugae to identify gender.

Materials and methods: This study consists of a total of 50 participants (25 males and 25 females). Participants of the age range of 20 to 50 years were selected from the outpatient department. According to the shape and size of the patient's arches, maxillary impression trays were selected using alginate, and casts were poured subsequently. With the help of a sharp graphite pencil, the palatine ridges were delineated to make it prominent, and on either side of the midline, the number of rugae was counted and the length measured. Using these parameters, the pattern of rugae was determined. Data were analyzed using independent sample t-test. The level of significance was set at $5 \%$.
\end{abstract}

Results: Males had more number of palatal rugae (mean 5.96 $\pm 0.88)$ compared with females $(5.24 \pm 0.77)$, and there was a statistically significant association between them. The mean length of palatal rugae was more in males $(6.25 \pm 1.15 \mathrm{~mm})$ than females $(5.16 \pm 1.40 \mathrm{~mm})$, and it was found to be a statistically significant association. The straight pattern was more common in both males and females (2.56 $\pm 1.08,2.32 \pm 0.85$ respectively) than other patterns.

Conclusion: This study concluded that straight rugae pattern has been found to be the most common pattern in both genders.

\footnotetext{
${ }^{1}$ Department of Prosthodontics and Dental Materials, Indira Gandhi Government Dental College and Hospital, Jammu Jammu and Kashmir, India

${ }^{2}$ Department of Dentistry, Karnataka Institute of Medical Sciences, Hubli, Karnataka, India

${ }^{3}$ Department of Prosthodontics, Nanded Rural Dental College \& Research Center, Nanded, Maharashtra, India

${ }^{4-6}$ Department of Prosthodontics, MNR Dental College and Hospital, Sangareddy, Telangana, India

Corresponding Author: Nitin Gautam, Department of Prosthodontics and Dental Materials, Indira Gandhi Government Dental College and Hospital, Jammu, Jammu and Kashmir India, e-mail: nitingautam212@gmail.com
}

However, the mean number of straight rugae pattern and length is slightly more in males than females.

Clinical significance: The most challenging tasks in forensic medicine is human identification. Dental records, dactylogram, and comparing deoxyribonucleic acid are the widely used techniques in mass disasters, but these techniques have their own drawbacks and hence cannot be applied always. In such cases, less known techniques like rugoscopy will be helpful.

Keywords: Forensic odontology, Gender, Palatal rugae, Personal identity.

How to cite this article: Gautam N, Patil SG, Krishna RG, Agastya $\mathrm{H}$, Mushtaq L, Kumar KV. Association of Palatal Rugae Pattern in Gender Identification: An Exploratory Study. J Contemp Dent Pract 2017;18(6):470-473.

\section{Source of support: Nil}

Conflict of interest: None

\section{INTRODUCTION}

Forensic odontology also known as legal dentistry is a branch of dentistry which involves applied sciences for medicolegal identification and holds a primary niche in the field. It can be defined as the application of principles of diagnostic dentistry to identifying remains of persons whose death occurred under uncertain circumstances. ${ }^{1}$

The basis of forensic odontology is the identification of deceased and establishing individual identity. Positive identification methods and exclusionary methods aid in personal identification. ${ }^{2}$ Widely used methods to identify are analysis of deoxyribonucleic acid, dactylogram, and comparing dental record ante- and postmortem. When the body is burnt or decomposed, these methods are not helpful. ${ }^{2}$ At such instances, palatal rugae come into place in establishing personal identity. It also serves as a tool for identification in edentulous patients, when teeth cannot be used for identification.

Synonyms for palatine rugae are plicae palatinae transversae or rugae palatine. They are the anatomical 
folds that are asymmetrically and irregularly present in the anterior one-third of the palate. Their origin is from the connective tissue of palatine process of maxillary bone around 3rd month of intrauterine life. The formation and growth of the rugae are under the control of epithelial-mesenchymal interactions and few particular extracellular matrix molecules. The lateral membrane of the incisal papilla is the origin of palatal rugae. ${ }^{3}$ Palatal rugae can be used in medicolegal identification processes because they are stable over time and are comparable to an individual's fingerprint. They have the ability to resist decomposition and to remain stable with respect to age and also resist destruction by trauma or surgical procedures because they are protected by the lip, cheeks, teeth, and buccal pad of fat. ${ }^{4}$

Being the soft tissue, they remain unchanged during high or extreme temperatures or severe physical injury. They are easily accessible over the entire lifetime and also remain unchanged for a long time after death, hence it is known as the most protected soft tissue. ${ }^{5}$ Because of this particular characteristic of palatal rugae, attempts are made to use these in forensics. Hence, the present study was conducted to assess plica palatine (palatal rugae) pattern in gender identification.

\section{MATERIALS AND METHODS}

This study consists of a total of 50 participants ( 25 males and 25 females) aged 20 to 50 years. Ethical clearance was obtained from the Indira Gandhi Government Dental College and Hospital, and consent was obtained from each participant before the study. Individuals with palatal asymmetries, with a history of palatal surgery or orthodontic treatment, and with lesions causing mucosal or bony changes in the maxillary anterior region were excluded.

\section{Maxillary Impression}

Maxillary impression (Fig. 1A) trays were selected according to the shape and size of the patient's arches. Two levels of alginate impression material were taken in the scoop and mixed with $40 \mathrm{~mL}$ of water (using a measuring jar provided by the manufacturer), in a water/powder ratio of $40 \mathrm{~mL}: 15 \mathrm{gm}$, in a flexible rubber bowl with a mixing spatula. A vigorous figure-of-eight motion was used for mixing. The mix was immediately transferred to the impression tray for insertion into the patient's mouth. The tray was held passively and motionless during the setting of impression material. After about 2 minutes (setting time of alginate), the tray was separated quickly from the teeth to avoid rocking and possible deformation of the fine areas of the impression. Excess material at the periphery was trimmed, and casts were poured subsequently.

\section{Palatal Rugae Tracing}

The oral examination of the individuals was done by a single investigator. Dental stone casts were prepared from a total of 50 impressions (Fig. 1B). To reduce intraobserver variations, each cast was analyzed twice. The ridges or folds (rugae) were made prominent using a sharp graphite pencil, later the number of rugae on either side of the midline was counted and the length measured. The pattern of rugae was determined using Thomas and Kotze classification. ${ }^{6}$ It classifies the rugae pattern into straight, wavy, circular, and curved (Fig. 1C). ${ }^{2}$

\section{Statistical Analysis}

To analyze the data, Statistical Package for the Social Sciences version 20 was used. Independent sample t-test was used to analyze data. The level of significance was set at $5 \%$.

\section{RESULTS}

Table 1 shows the association between gender and mean number of palatal rugae. Males had more number of palatal rugae (mean $5.96 \pm 0.88$ ) compared with females $(5.24 \pm 0.77)$, and there was a statistically significant association between them. The mean length of palatal rugae was more in males $(6.25 \pm 1.15 \mathrm{~mm})$ than females $(5.16 \pm 1.40 \mathrm{~mm})$. Moreover, it was found to be a statistically significant association (Table 2). Table 3 reveals that the straight pattern was more common in both males and females $(2.56 \pm 1.08,2.32 \pm 0.85$ respectively $)$ than other patterns. However, none of the pattern shows a statistically significant association between the different patterns with gender.

\section{DISCUSSION}

Palatal rugae facilitate personal identification procedures with its uniqueness, postmortem resistance, and constancy; therefore, it is an ideal forensic parameter. ${ }^{7}$ Several authors showed the diversity of rugae patterns and their sex identification potential among different ethnic groups with different results. Because of this uncertainty, we tried to assess the distinctiveness of the palatal rugae patterns if any, to characterize this regional sample.

In this study, the mean straight pattern was more among males and mean circular pattern was the least among females. These results are in contrary to the study conducted by Paliwal et $\mathrm{al}^{8}$ and Kallianpur et al, ${ }^{9}$ who said that the predominant shape was wavy. Intergroup comparisons of rugae shape revealed that the curved type was more among males and the wavy type higher 

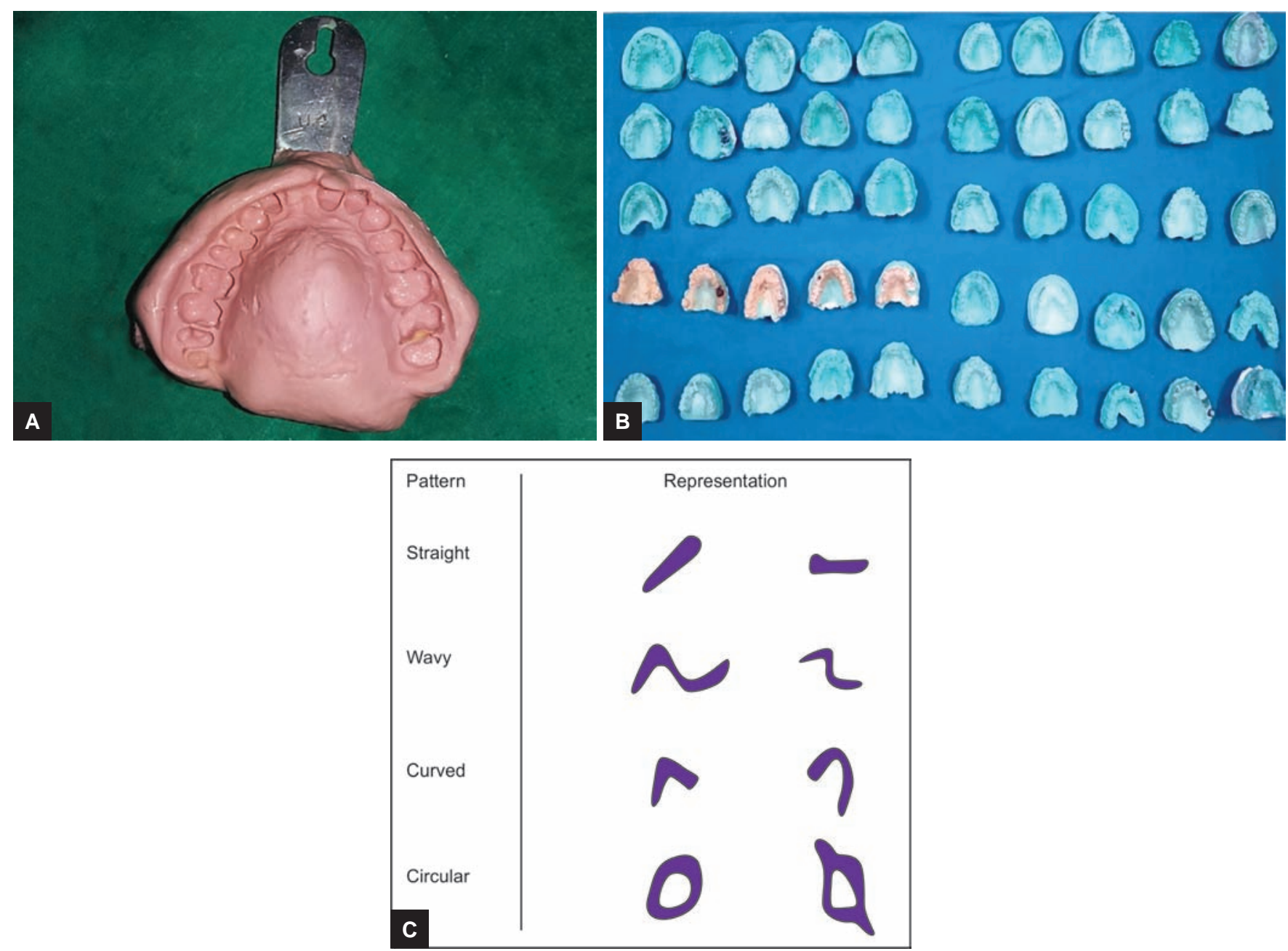

Figs 1A to C: (A) Maxillary alginate impression; $(B)$ master casts with palatal rugae tracing; and (C) different pattern of palatal rugae

Table 1: Association between gender and mean number of palatal rugae

\begin{tabular}{|c|c|c|c|c|c|}
\hline & Gender & $n$ & $\begin{array}{l}\text { Mean } \pm \\
\text { standard } \\
\text { deviation }\end{array}$ & $\begin{array}{l}\text { Standard } \\
\text { error } \\
\text { mean }\end{array}$ & $p$-value \\
\hline \multirow{2}{*}{$\begin{array}{l}\text { Number of } \\
\text { palatal rugae }\end{array}$} & Male & 25 & $5.96 \pm 0.889$ & 0.178 & $0.004^{*}$ \\
\hline & Female & 25 & $5.24 \pm 0.779$ & 0.156 & \\
\hline
\end{tabular}

*Statistically significant

Table 3: Association between gender and mean of palatal rugae pattern

\begin{tabular}{llllll}
\hline \multirow{6}{*}{ Curved } & & & $\begin{array}{l}\text { Mean } \pm \\
\text { standard } \\
\text { deviation }\end{array}$ & $\begin{array}{l}\text { Standard } \\
\text { error of } \\
\text { mean }\end{array}$ & $p$-value \\
\hline \multirow{6}{*}{ Wavy } & Male & 25 & $1.66 \pm 0.816$ & 0.163 & 1.0 \\
& Female & 25 & $1.60 \pm 0.577$ & 0.115 & \\
& Male & 25 & $1.28 \pm 0.678$ & 0.136 & 0.069 \\
\multirow{2}{*}{ Circuight } & Female & 25 & $0.88 \pm 0.833$ & 0.167 & \\
& Male & 25 & $2.56 \pm 1.083$ & 0.217 & 0.38 \\
& Female & 25 & $2.32 \pm 0.852$ & 0.170 & \\
& Male & 25 & $0.52 \pm 0.586$ & 0.117 & 0.6 \\
& Female & 25 & $0.44 \pm 0.507$ & 0.101 & \\
\hline
\end{tabular}

Table 2: Association between gender and mean length of palatal rugae

\begin{tabular}{|c|c|c|c|c|c|}
\hline & Gender & $n$ & $\begin{array}{l}\text { Mean } \pm \text { standard } \\
\text { deviation }\end{array}$ & $\begin{array}{l}\text { Standard } \\
\text { error of } \\
\text { mean }\end{array}$ & $p$-value \\
\hline \multirow{2}{*}{$\begin{array}{l}\text { Length } \\
\text { of palatal } \\
\text { rugae }\end{array}$} & Male & 25 & $6.2564 \pm 1.15421$ & 0.23084 & $0.003^{\star}$ \\
\hline & Female & 25 & $5.1664 \pm 1.40638$ & 0.28128 & \\
\hline
\end{tabular}

in females, which was statistically significant. Chatterjee and Khanna ${ }^{10}$ and Saraf et al. ${ }^{1}$ showed a significant difference in the converging type in females and circular type in males.

The typical arrangement of the plica palatine does not change due to growth and remains unchanged from fetus to death. Events, such as physical injury, habitual finger sucking from infancy, orthodontic treatment, and dentures can cause change in rugae patterns. ${ }^{11}$ Changes in rugae form seen in diseases, chemical aggression, or trauma are less intense than those which happens to the whole body. Until 7 days postdeath, the palatal rugae can resist decomposition. ${ }^{11}$ 
According to the present study, females have statistically significant reduced number of mean rugae than males. This result is similar to the study conducted by Bharath et $\mathrm{al}_{1}{ }^{12}$ Dohke and Osato ${ }^{13}$ who reported that among the Japanese, females have lesser number of rugae than males. These findings indicate racial and gender differences in rugae patterns.

The mean length of the present study shows statistically significant higher length among males than females. These results were in contrary to the study done by Selvamani et $\mathrm{al}^{14}$ in which there was no statistically significant difference in the length of palatal rugae between males and females of Kerala.

The present study successfully established the individuality of the rugae patterns, length, and number. However, major drawback is that large-scale studies are necessary. Conversely, multicentered research among different ethnic groups is essential for a more comprehensive understanding of the role of palatal rugae in the realm of forensic odontology.

\section{CONCLUSION}

According to the present study, it is concluded that straight rugae pattern is most common in both groups, and the mean number of palatal rugae and length is slightly more in males than females. Thus, palatal rugae pattern is definitely a sufficient characteristic to discriminate between the genders, within the limitation of the study which requires further large-scale studies to support the hypothesis on the uniqueness of the palatal rugae, which eases identification in forensic dentistry.

\section{REFERENCES}

1. Saraf A, Bedia S, Indurkar A, Degwekar S, Bhowate R. Rugae patterns as an adjunct to sex differentiation in forensic identification. J Forensic Odontostomatol 2011 Jul;29(1):14-19.
2. Subramanian P, Jagannathan N. Palatal rugoscopy as a method of sex determination in forensic science. Asian J Pharm Clin Res 2015 Jan;8(2):136-138.

3. Venegas VH, Valenzuela JS, Lopez MC, Galdames IC. Palatal rugae: systematic analysis of its shape and dimensions for use in human identification. Int J Morphol 2009 Sep;27(3):819-825.

4. Limson KS, Julian R. Computerized recording of the palatal rugae pattern and an evaluation of its application in forensic identification. J Forensic Odontostomatol 2004 Jun;22(1):1-4.

5. Muhasilovic S, Hadziabdic N, Galic I, Vodanovic M. Analysis of palatal rugae in males and females of an average age of 35 in a population from Bosnia and Herzegovina (Sarajevo Canton). J Forensic Leg Med 2016 Apr;39:147-150.

6. Thomas CJ, Kotze TJ. The palatal ruga pattern in six southern African human populations, part I: a description of the populations and a method for its investigation. J Dent Assoc S Afr 1983 Mar;38(9):547-553.

7. Wichnieski C, Franco A, Ignácio SA, Batista PS. Comparative analysis between dactyloscopy and rugoscopy. J Morphol Sci 2012 Sep;29(3):174-177.

8. Paliwal A, Wanjari S, Parwani R. Palatal rugoscopy: establishing identity. J Forensic Dent Sci 2010 Jan;2(1):27-31.

9. Kallianpur S, Desai A, Kasetty S, Sudheendra U, Joshi P. An anthropometric analysis of facial height, arch length, and palatal rugae in the Indian and Nepalese population. J Forensic Dent Sci 2011 Jan;3(1):33-37.

10. Chatterjee S, Khanna M. Dimensional analysis of various rugae patterns in north Indian population subset. J Forensic Dent Sci 2011 Jul;3(2):86-88.

11. Swetha S. Palatal rugae pattern in varied adult Indian population of males and females. J Pharm Sci Res 2015 Sep;7(9):736-739.

12. Bharath ST, Kumar GR, Dhanapal R, Saraswathi T. Sex determination by discriminant function analysis of palatal rugae from a population of coastal Andhra. J Forensic Dent Sci 2011 Jul;3(2):58-62.

13. Dohke M, Osato S. Morphological study of the palatal rugae in Japanese. I. Bilateral differences in the regressive evaluation of the palatal rugae. Jpn J Oral Biol 1994 Jan;36(2):125-140.

14. Selvamani M, Hosallimath S, Madhushankari, Basandi PS, Yamunadevi A. Dimensional and morphological analysis of various rugae patterns in Kerala (South India) sample population: a cross-sectional study. J Nat Sci Biol Med 2015 Jul-Dec;6(2):306-309. 